\title{
Distribution of Dental Chairs in Duhok City According to their Manufacture Origin, And Their Need to Replace the Failure Parts
}

\author{
Ameena Abdullah $^{1}$, Abdullqadir Majeed ${ }^{2}$ and Bahar Selivany ${ }^{2}$ \\ ${ }^{I}$ Health Directorate, 1006AJ Duhok City, Kurdistan Region - Iraq \\ ${ }^{2}$ College Of Dentistry, University Of Duhok, 1006AJ Duhok City, Kurdistan Region - Iraq
}

\begin{abstract}
The aim of the study was to find the way of distribution of dental chairs in Duhok City and to evaluate the need for replacement of the damage parts. In addition to that to compare the efficiency of dental units in the College of dentistry with those in poly clinic in Duhok City.100 dental chairs were involved in this study, questioner was prepared for this reason and was filled by taking the information from the engineer responsible for maintaining the unit. A scores were chosen to measure the no. of the damage parts selected previously .the result showed that the distribution of the units were from different companies due to their import in different time interval, and the Aedic dental chairs (USA) showed the largest distribution and better performance. In conclusion one can say Aedic dental chairs need the least replacement.
\end{abstract}

Keywords: Dental chairs, Manufacture origin, failure parts.

\section{Introduction}

Dental chairs in Duhok city were imported from different countries and companies. The reason of that they were imported in different time intervals according to the development that was takes place in Duhok city. The first company that started manufacturing of the dental chairs was SS White Company, first dental chair constructed by this company Harris chair in 1871, it was made of full metal, all of the movement to upward, downward, and head and foot reset were done by hand. In 1872 another dental chair was constructed by this company they call it Morrison Dental Chair it was fully adjustable dental chair. In1877 another dental chair manufactured by the SS White Company it was known as Wilkinson Dental Chair, it was characterized by hydrolytic foot pump to control the upward and down ward movement with removable arm seat and child seat .(1-8) In Germany Adam Schneider in1883 started to construct the dental chair in his company in Berlin, in 1890 first electric dental chair was introduced to the market by Adam Schneider but unfortunately it was not fully adjustable in all direction and position, in 1891 Adam Schneider over came all of the previously mentioned problem by addition of internal attachment like cautery, warm air blower, large spittoon and massive leather for the dental chair, also he positioned the motor and low current instrument on a floor stand, this dental chair was the most famous chair in Europe but it was so expensive therefore was difficult for the dentist from united Kingdom to buy it.(5)

As a replacement for the absence of the electricity in many cities of United Kingdom at the beginning of $20^{\text {th }}$ century the dentists used lead acid batteries because the foot drill was unknown at that time. In 1883 dental light was first time used in dental chair especially during surgical operation, before that day light was used. In 1920 all dental equipment's were placed at the left side of the dental chair this made difficulties for the left handed dentists because this made them to sit at the side near the spittoon. In 1960 dental turbine that operate via air from the compressor was discovered and this made possible to arrange the dental equipment and accessories in both left and right side in such a way that the dentist and the nurse postioned opposite to each other and from this situation the idea of 4 handed dentistry was started.(9-12)

In Duhok health centers and at the beginning of 1970 the first dental chairs were imported from Japan, (Ushida company) in the general hospital this was followed by another dental units from Japan also, (Belmont Company) in 1980. The next imported unit were from Germany, (Siemens Company) in 1998, this followed by another package from China in 2000 and over, (Foshion, ziane, sager companies). In the recent years the college of dentistry in Duhok University received 60 units, these units were used for training different aspect of dentistry and dental treatment, in addition to that about 40 units were installed in other health centers in Duhok city. There is no previous data or information concerning the efficiency of these dental chairs since they have imported to be used.

Aims of the study:

1) To determine the distribution of different dental unit in Duhok city regarding dental clinic in college of dentistry and poly dental clinic in Duhok health directorate. 
2) To compare the efficiency of dental chairs by evaluating their need to repair and frequency to replace the damage parts.

\section{Method}

A survey and questioner was done to different Governorate dental clinic in Duhok City to examine and evaluate (100) dental chair. The efficiency of dental chair after three years of service was evaluated by asking the dentist and service engineer about the quality and efficiency of the different parts of the chair used according to tables prepared previously. Different categories were taken into consideration regarding the manufacturer origin, position of installation, trouble shooting, and needs of replace the damage parts. These data compared with standard equipment of dental chair which should contain the following instrument in their perfect efficiency at work:

These are: projecting light, Turbine, Hand piece, Triple syringe, Light cures, Dental Scalar and Dental Sucker. A scoring system was employed to Assis the quality of the dental unit according to the failure part or parts.

- $\quad$ Score zero means no failure (excellent).

- $\quad$ Score one failure of 1-2 parts (very good).

- $\quad$ Score two failure of 3-4 parts (good).

- Score three failure of 5-6 (fair).

- $\quad$ Score four failure of 7 (impaired).

Data obtained were subjected to statistical analysis.

\begin{tabular}{|c|c|c|}
\hline Score & No. of Failure & Evaluation \\
\hline 0 & No Failure & Excellent \\
\hline 1 & $1-2$ parts & Very Good \\
\hline 2 & $3-4$ parts & Good \\
\hline 3 & $5-6$ parts & Fair \\
\hline 4 & 7 parts & Impaired \\
\hline
\end{tabular}

\section{Check list}

1. Name of health center

2. Type of dental unite

3. Period of operation

4. Type of failure of dental unite

\section{- Turbine \\ - Hand piece \\ - $\quad$ Triple syringe \\ - $\quad$ Projecting light \\ - $\quad$ Light cure \\ - Dental scaler Dental sucker}

5. Score

Efficiency of dental unite

$\square$ Fail $\square$ fair good $\square$ ry good $\square$ ellent

\section{Results}

The Distribution of dental units in Duhok City according to origin and position were presented in table (1), figure (1-11).

Table (1) Distribution of dental unit in Duhok city

\begin{tabular}{|c|c|c|c|}
\hline Types of dental unit & No. & Location Area & Group \\
\hline \multirow[t]{8}{*}{ Sirona /Siemens manufacture } & \multirow{2}{*}{9} & \multirow{2}{*}{ Bamarny HC (No.1) } & Germany \\
\hline & & & Germany \\
\hline & & Chamanky HC (No. 1) & Germany \\
\hline & & Emergency Hosp. ( No. 1) & Germany \\
\hline & & Duhok HC ( No. 1 ) & Germany \\
\hline & & Khabour HC (No. 1) & Germany \\
\hline & & Baadry HC (No. 1) & Germany \\
\hline & & Dental Poly clinic (Qty 3) & Germany \\
\hline
\end{tabular}


Distribution of dental chairs in Duhok City According to their manufacture origin, and their need to

\begin{tabular}{|c|c|c|c|}
\hline \multirow[t]{23}{*}{ Copika manufacture } & 30 & Deralok HC (No.1) & Italy \\
\hline & & Amadia Hosp. (No. 1) & Italy \\
\hline & & Bamarny HC (No. 1) & Italy \\
\hline & & Bagera HC (No. 1) & Italy \\
\hline & & Khabat HC (No. 1) & Italy \\
\hline & & Emergency Hosp (No. 1) & Italy \\
\hline & & Barzan HC (No. 1) & Italy \\
\hline & & Shaheedan HC (No. 1) & Italy \\
\hline & & Shendokha HC (No. 1) & Italy \\
\hline & & Mateen HC (No. 1) & Italy \\
\hline & & Bahdeenan HC (No. 1) & Italy \\
\hline & & Duhok HC (No. 1) & Italy \\
\hline & & Dental poly clinic (No. 8) & Italy \\
\hline & & Tanahy HC (No. 1) & Italy \\
\hline & & Khanky HC (No. 1) & Italy \\
\hline & & Saeed peeran HC (No. 1) & Italy \\
\hline & & khabour HC (No. 1) & Italy \\
\hline & & Bateefa HC (No. 1) & Italy \\
\hline & & Dalal HC (No. 1) & Italy \\
\hline & & Denarta HC (No. 1) & Italy \\
\hline & & Bardarash HC (No. 1) & Italy \\
\hline & & Kalakchy HC (No. 1) & Italy \\
\hline & & Qasrok HC (No.1) & Italy \\
\hline \multirow[t]{2}{*}{ Sweednt manufacture } & 2 & Azady Hosp. (No. 1) & Italy \\
\hline & & Sarseng HC (No. 1) & Italy \\
\hline \multirow[t]{9}{*}{ Castiliny manufacture } & 9 & Kany masy HC (No. 1 ) & Italy \\
\hline & & Kazy Mihammed HC (No. 1) & Italy \\
\hline & & Darkar HC (No. 1) & Italy \\
\hline & & Douban HC (No. 1) & Italy \\
\hline & & Sharia HC (No. 1) & Italy \\
\hline & & Barzan / zakho HC (No. 1) & Italy \\
\hline & & Telkabar HC (No. 1) & Italy \\
\hline & & Bateefa HC (No. 1) & Italy \\
\hline & & Khazer HC (No. 1) & Italy \\
\hline \multirow[t]{3}{*}{ Anthuse maneufacture } & \multirow{3}{*}{4} & \multirow{2}{*}{ Zanest HC (No. 2 ) } & Italy \\
\hline & & & Italy \\
\hline & & 11 Adar HC (No. 2) & Italy \\
\hline \multirow[t]{6}{*}{ Siger maneufacture } & 6 & Shealadzy HC (No. 1) & Chines \\
\hline & & Qadesh HC (No. 1) & Chines \\
\hline & & Zaweita HC (No. 1) & Chines \\
\hline & & Mangesh HC (No. 1) & Chines \\
\hline & & Mesereiky HC (No. 1) & Chines \\
\hline & & Zakho Hosp. (No. 1) & Chines \\
\hline \multirow[t]{5}{*}{ Ziane maneufacture } & \multirow{2}{*}{5} & \multirow{2}{*}{ Sarhaldan HC ( Qry. 1) } & Chines \\
\hline & & & Chines \\
\hline & & Zerka prison HC ( Qry. 1) & Chines \\
\hline & & Dental poly clinic ( Qry. 1) & Chines \\
\hline & & Goulan Hospital (No. 2) & Chines \\
\hline Aedic maneufacture & & University of Duhok college of & \\
\hline & & Denistry & USA \\
\hline \multirow{5}{*}{ Aedic model 300} & 36 & Surgery Dep. (No. 2) & USA \\
\hline & & $\begin{array}{l}\text { Paedo - prevention Dep. (No. } \\
\text { 12) }\end{array}$ & USA \\
\hline & & Perio Dep. (No. 12 ) & USA \\
\hline & & Conservative Dep. (No. 10) & USA \\
\hline & & $\begin{array}{l}\text { Note : } 2 \text { machine of Aedic } \\
\text { model } 300 \text { in storage }\end{array}$ & USA \\
\hline \multirow[t]{2}{*}{ Aedic model 200} & 18 & Surgery Dep. (No. 8) & USA \\
\hline & & Prosthetic Dep. (No. 10) & USA \\
\hline \multirow[t]{2}{*}{ Yoshida manufacture } & 2 & Emergency Hospital (No. 1) & Japan \\
\hline & & Malta HC (No. 1) & Japan \\
\hline & & & \\
\hline & & & \\
\hline
\end{tabular}




\section{Distribution of dental Chairs in Duhok City}

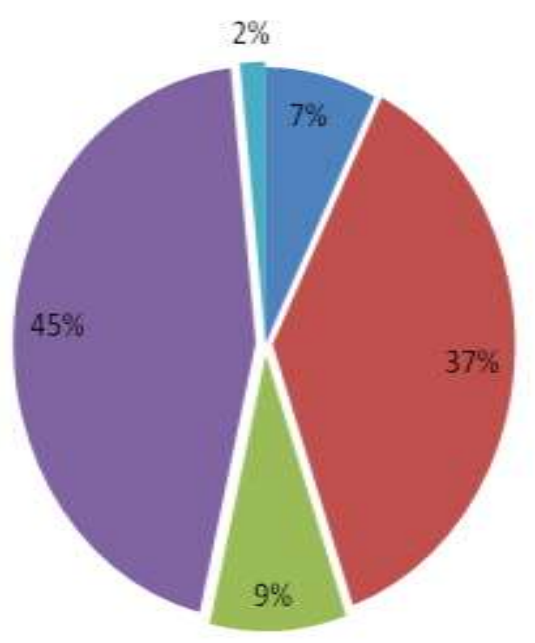

nermany

- Italy

in Chines

- USA

I Japan

Figure (1) Percentages of Dental Chairs according to their origin

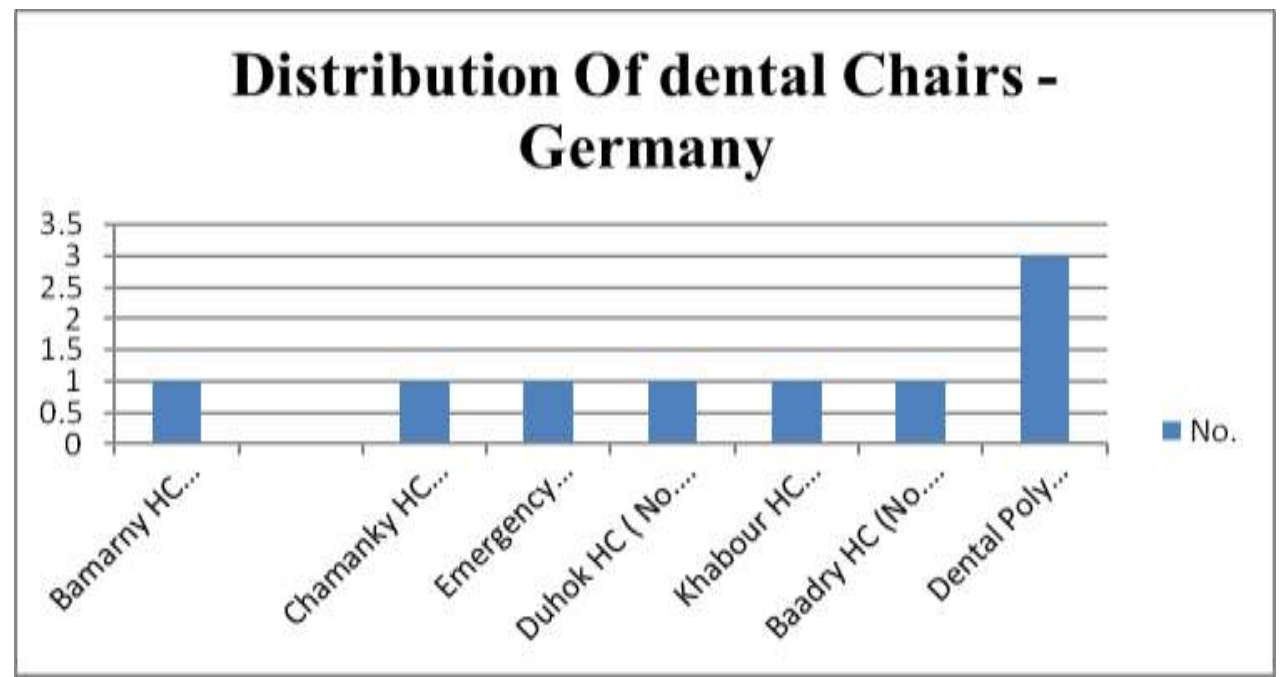

Figure (2) Distribution of the German Dental Chairs in Duhok City

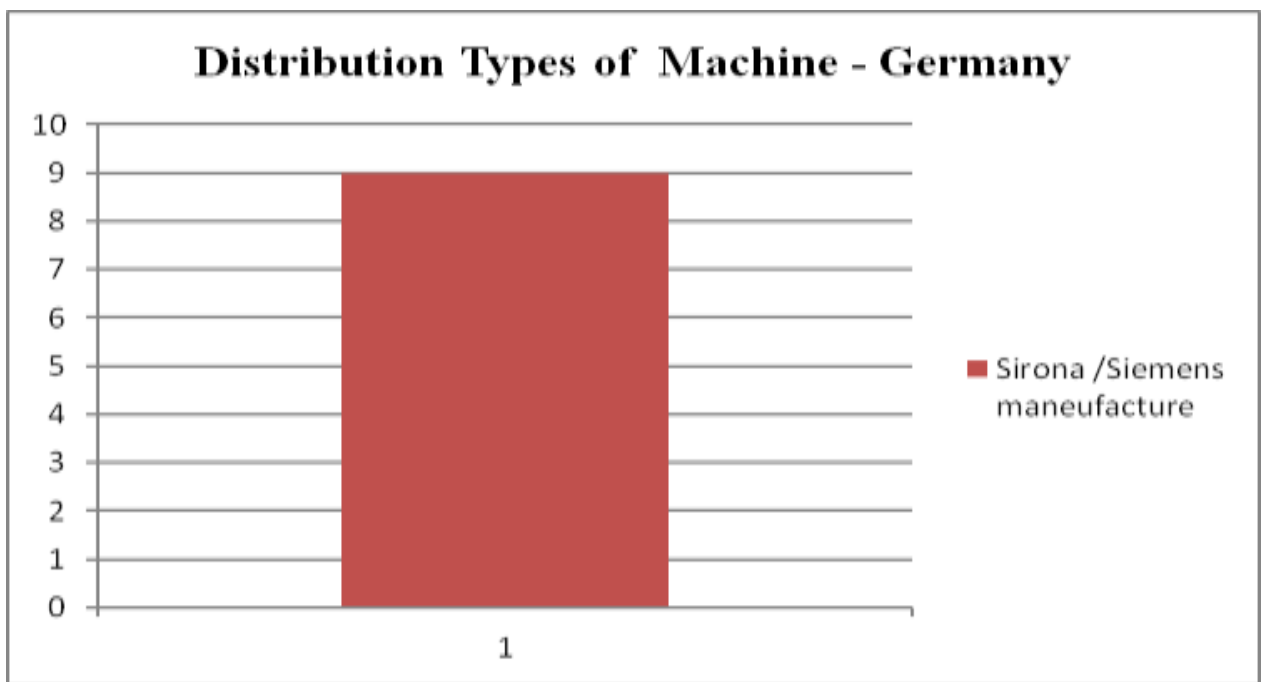

Figure (3) Distribution of Germany dental chairs (Sirona) in Duhok City 


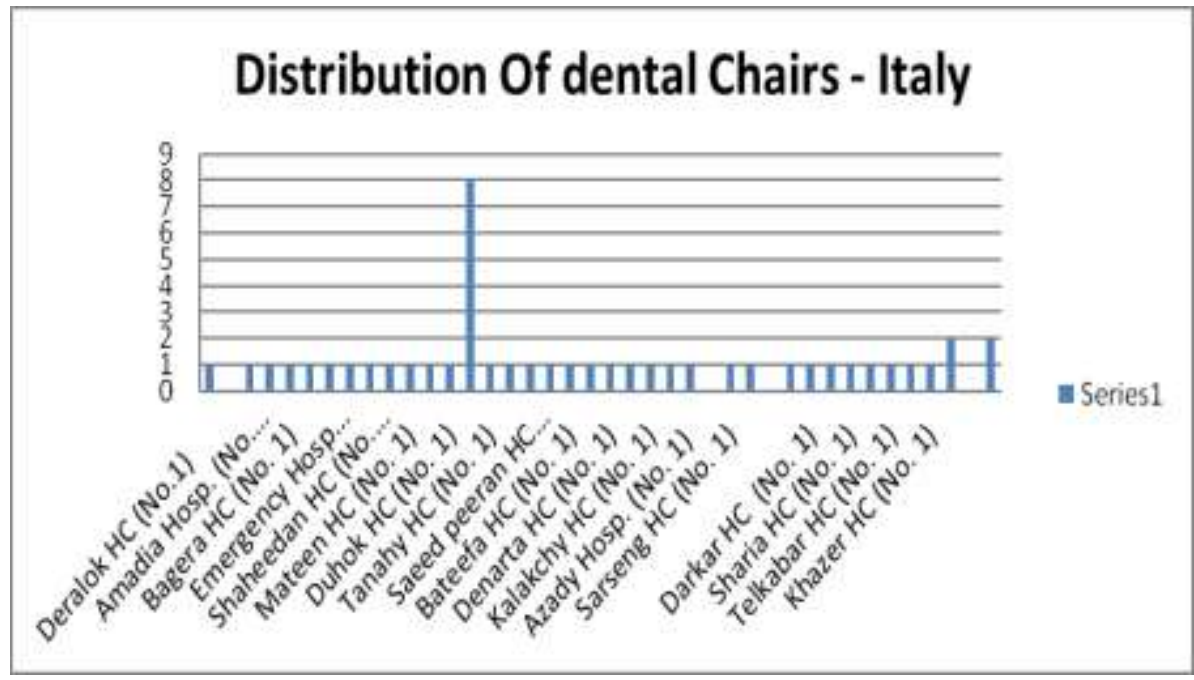

Figure (4) Distribution of the Italian Dental Chairs in Duhok City

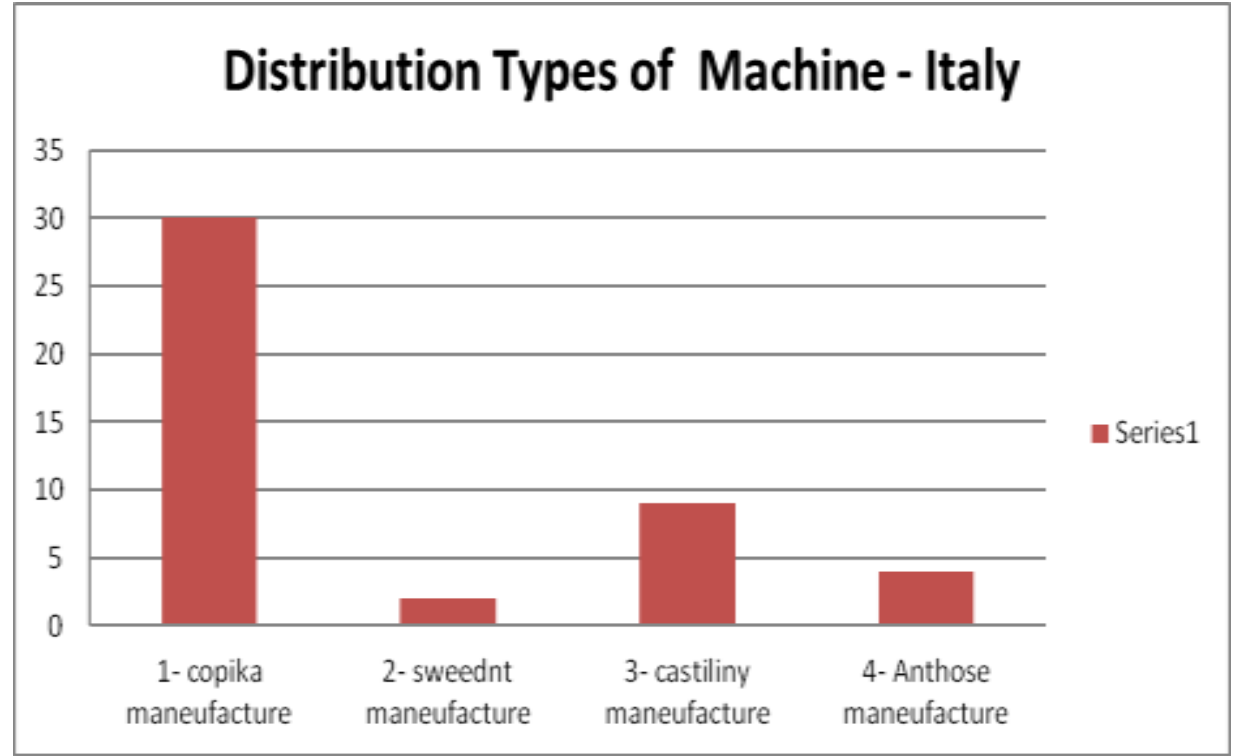

Figure (5) Distribution of Italian dental chairs in Duhok City

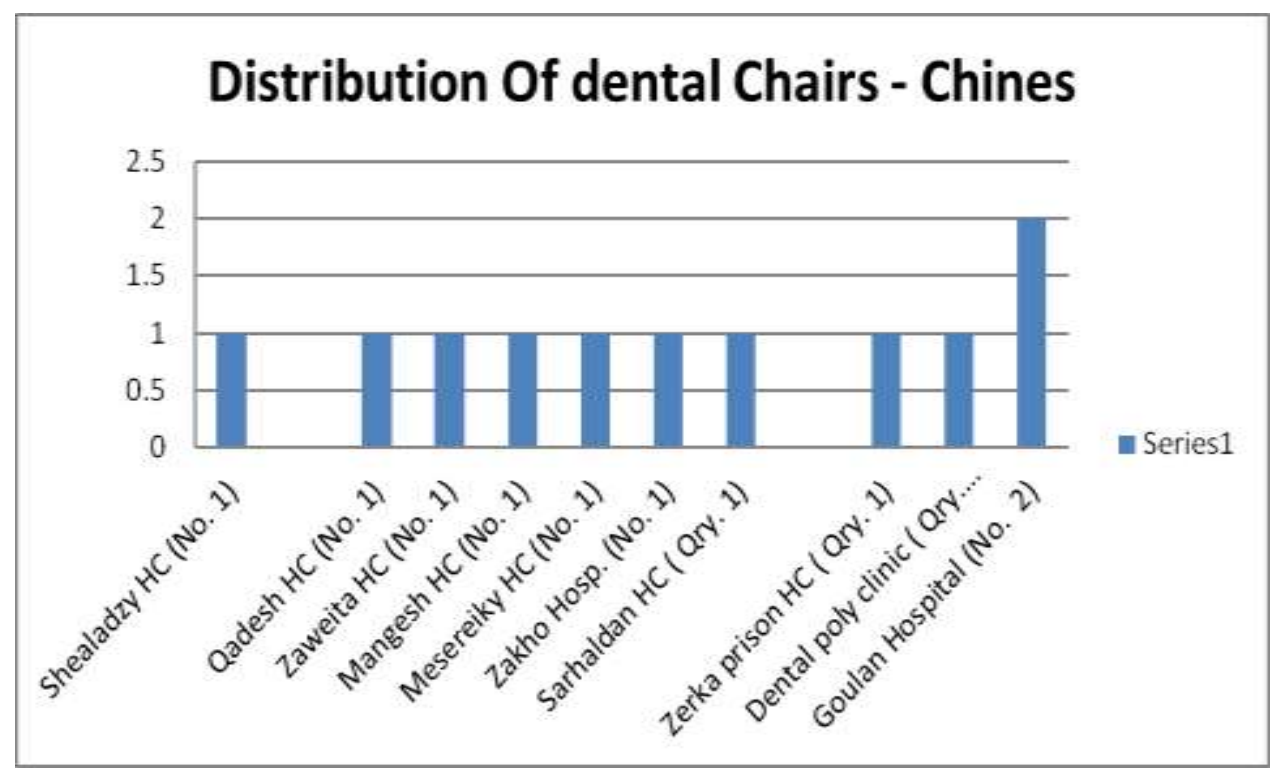

Figure (6) Distribution of the Chines Dental Chairs in Duhok City (Health center) 


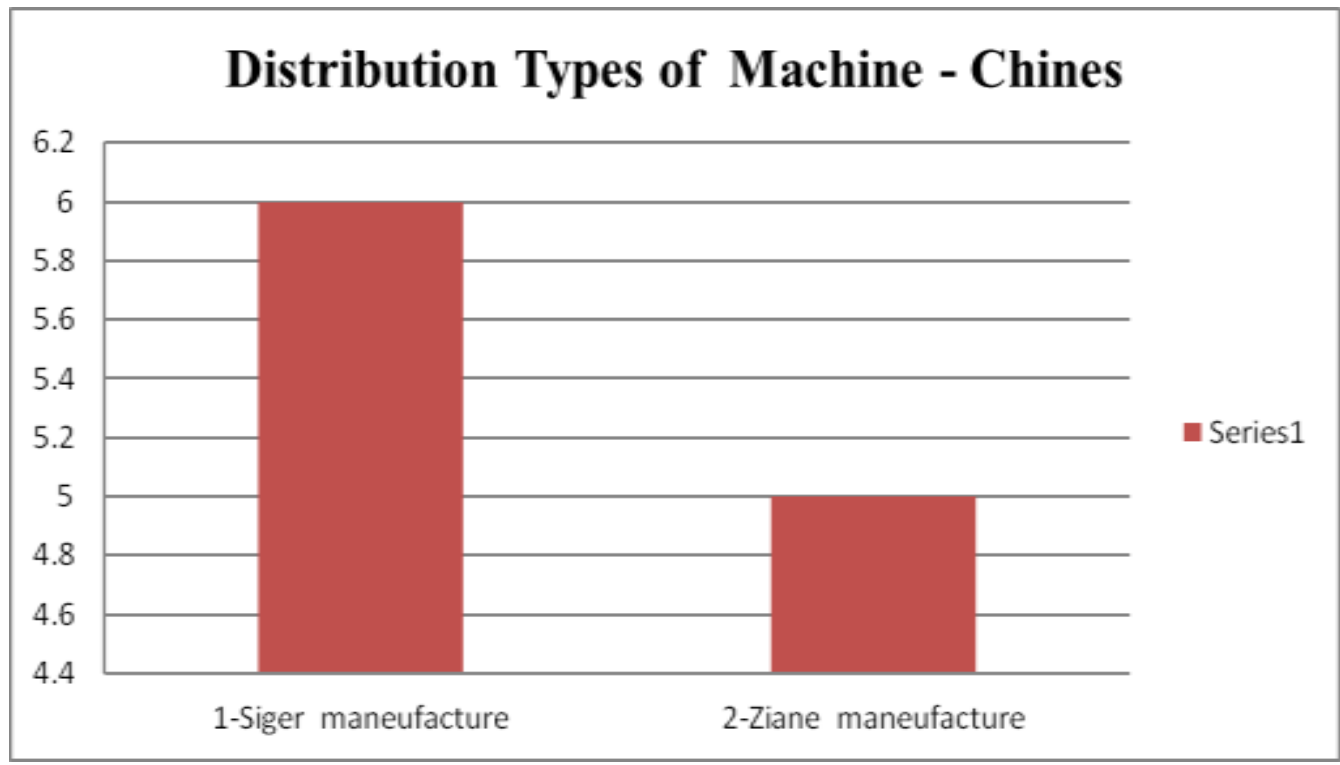

Figure (7) Main Chines Dental Chairs Distributed in Duhok City

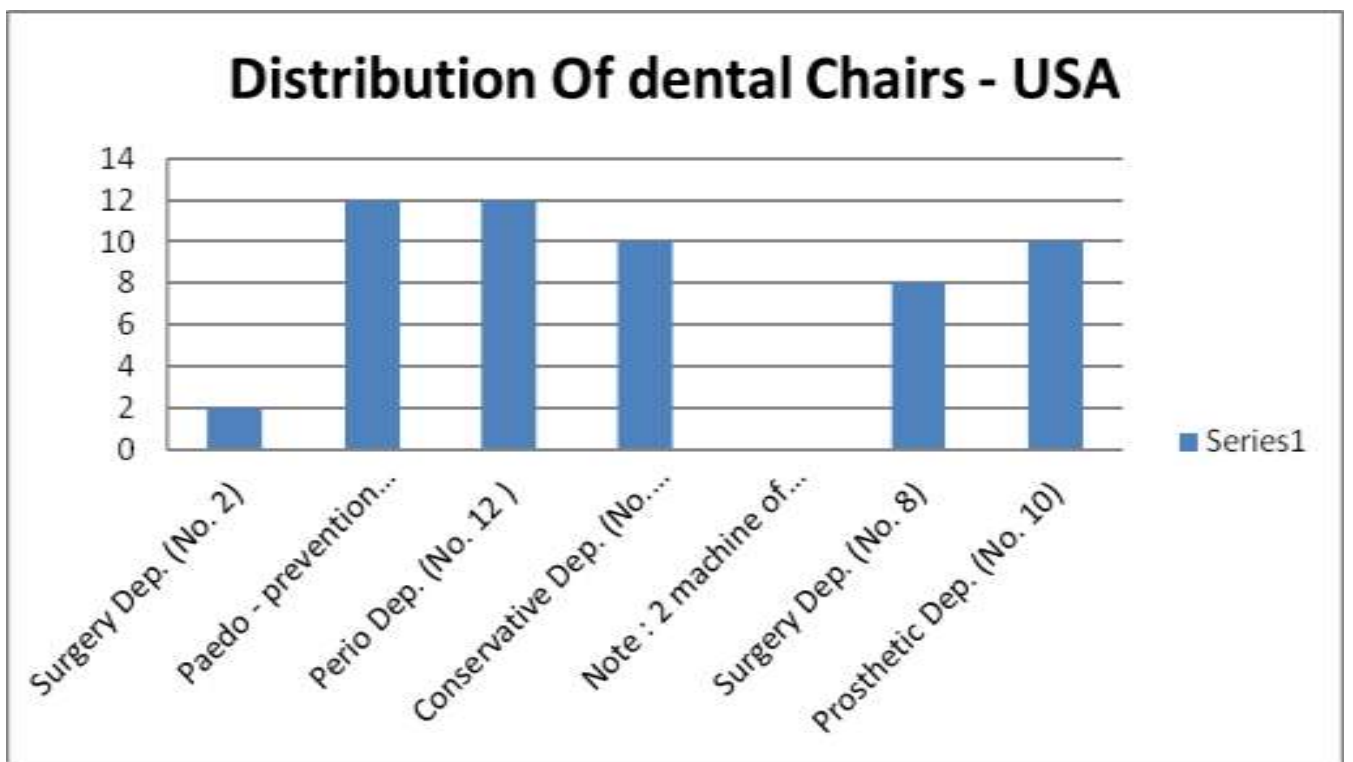

Figure (8) Distribution of the USA Dental Chairs in Duhok City

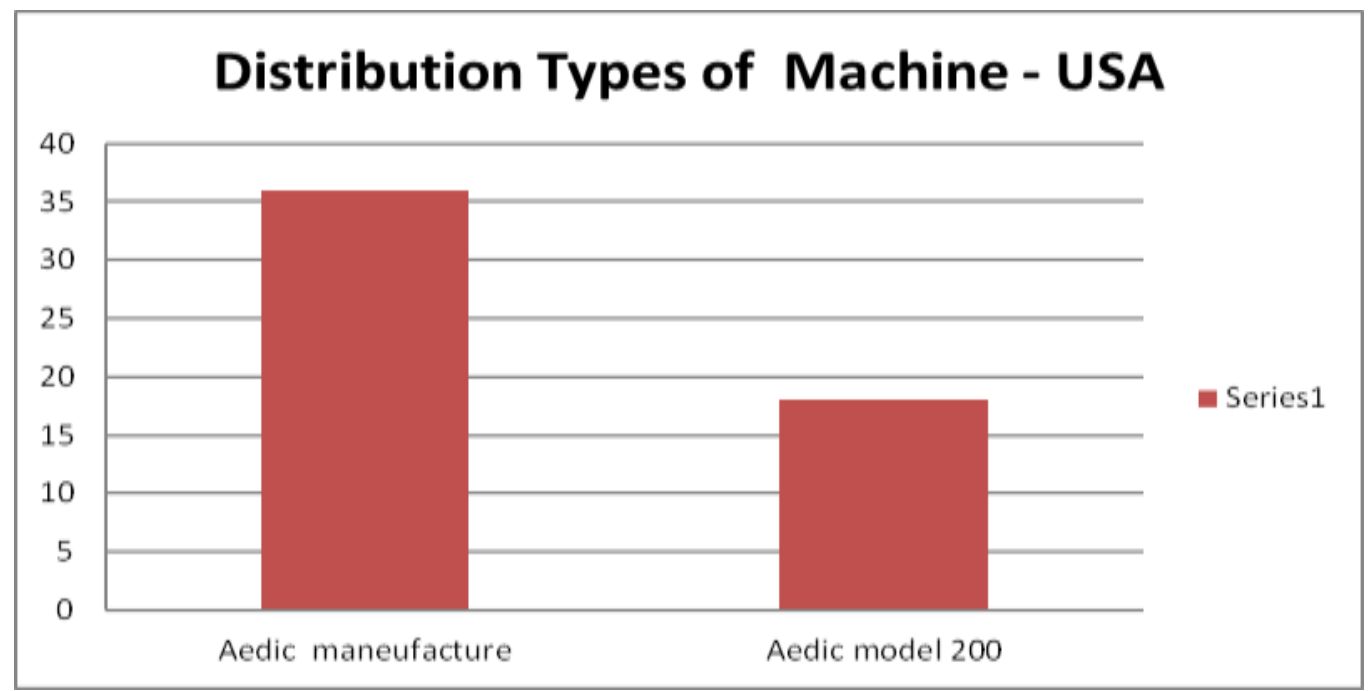

Figure (9) Main USA Dental Chairs Distributed in Duhok City 


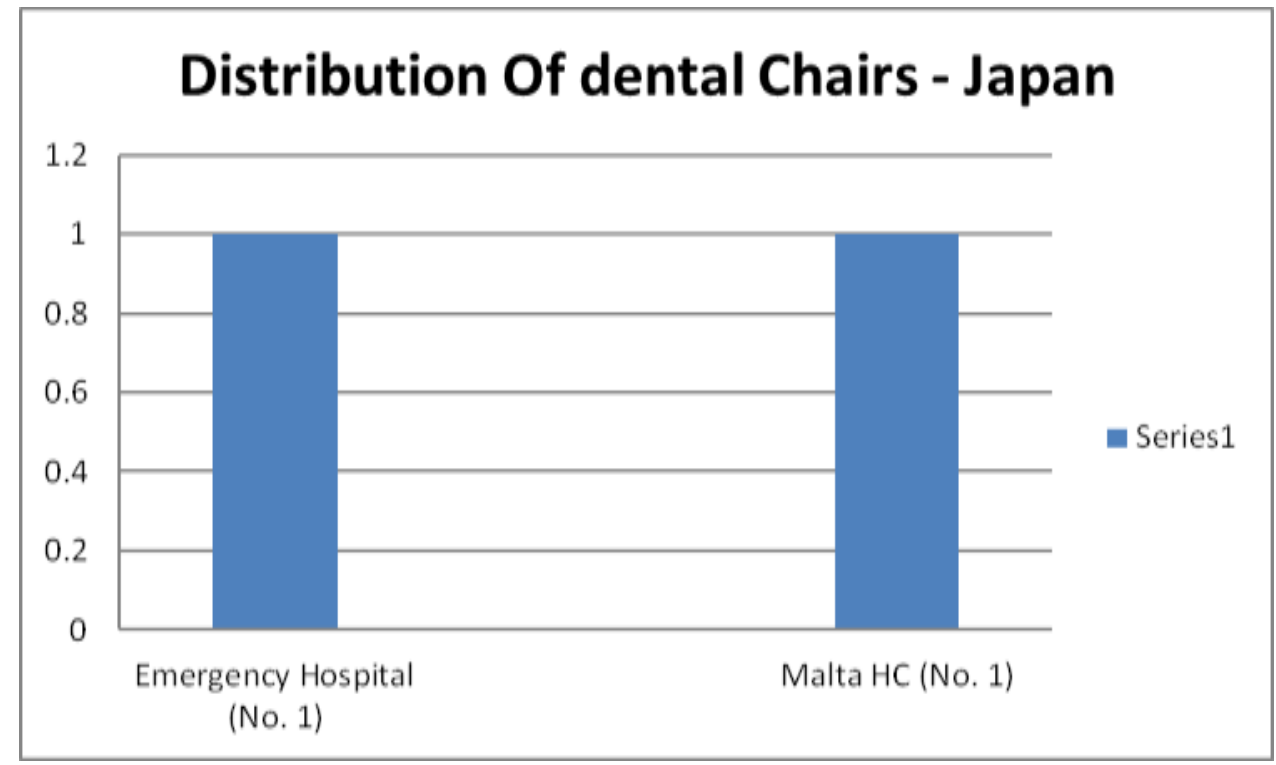

Figure (10) Distribution of the USA Dental Chairs in Duhok City

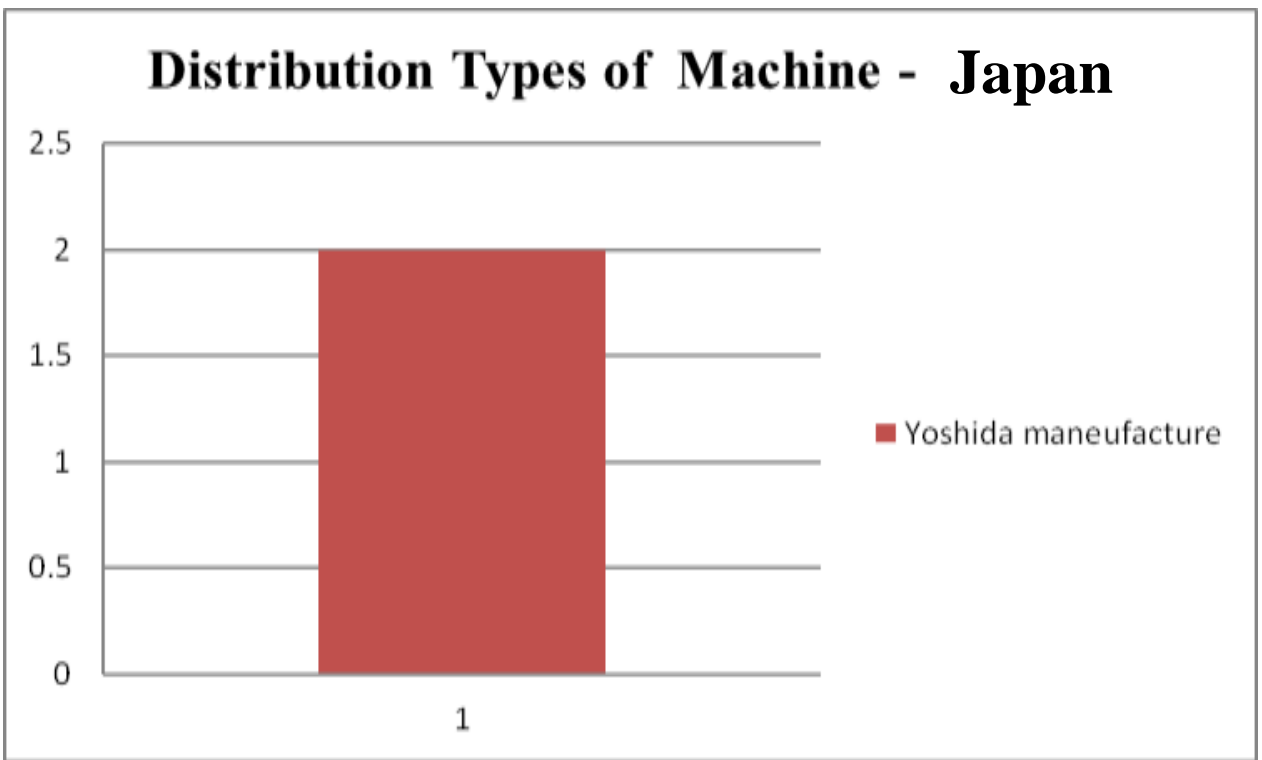

Figure (11) Main Japanese Dental Chairs Distributed in Duhok City

In order to find the differences in distribution of these dental units in different places in Duhok City and dental College, Mann-Whitney Test was performed and the results presented in table (2). There was a significant difference between college and dental clinic in dental unit.

\begin{tabular}{|c|c|c|}
\hline \multicolumn{3}{|c|}{$\begin{array}{l}\text { Table (2) Statistical analysis for the differences in distributions of Dental unit between } \\
\text { Dental College and polyclinic }\end{array}$} \\
\hline & department & Dental unit \\
\hline Mann-Whitney U & 36.500 & 1.000 \\
\hline Wilcoxon W & 141.500 & 22.000 \\
\hline $\mathrm{Z}$ & -0.458 & -3.462 \\
\hline Asymp. Sig. (2-tailed) & 0.647 & 0.001 \\
\hline Exact Sig. [2*(1-tailed Sig.)] & $0.659^{b}$ & $0.000^{\mathrm{b}}$ \\
\hline \multicolumn{3}{|l|}{ a. Grouping Variable: Types } \\
\hline b. Not corrected for ties. & & \\
\hline
\end{tabular}


Failure of Dental Poly Clinic in Duhok City

A statistical analysis was performed to find the differences of failure in different Departments of Dental Polyclinic \& the results revealed highly significant differences and these are presented in table (3) \&figure (12).

Table (3) Scoring failure in different Departments of Dental Polyclinic in Duhok City

\begin{tabular}{|c|c|c|}
\hline Department & Sample & Control \\
\hline Implant Dep. & 1 & 0 \\
\hline Prosthetic Dep. & 7 & 0 \\
\hline Diagnosis Dep. & 3 & 0 \\
\hline \multirow{2}{*}{ P.O.P Dep. } & 3 & 0 \\
\hline \multirow{2}{*}{ Surgical Dep. } & 2 & 0 \\
\cline { 2 - 3 } & 1 & 0 \\
\cline { 2 - 3 } & 0 & 0 \\
\hline \multirow{2}{*}{ Periodontics Dep. } & 7 & 0 \\
\cline { 2 - 3 } & 1 & 0 \\
\hline \multirow{3}{*}{ Restorative Dep. } & 3 & 0 \\
\cline { 2 - 3 } & 2 & 0 \\
\cline { 2 - 3 } & 2 & 0 \\
\cline { 2 - 3 } & 0 & 0 \\
\hline Azadi Center of Implant & 0 & 0 \\
\hline
\end{tabular}

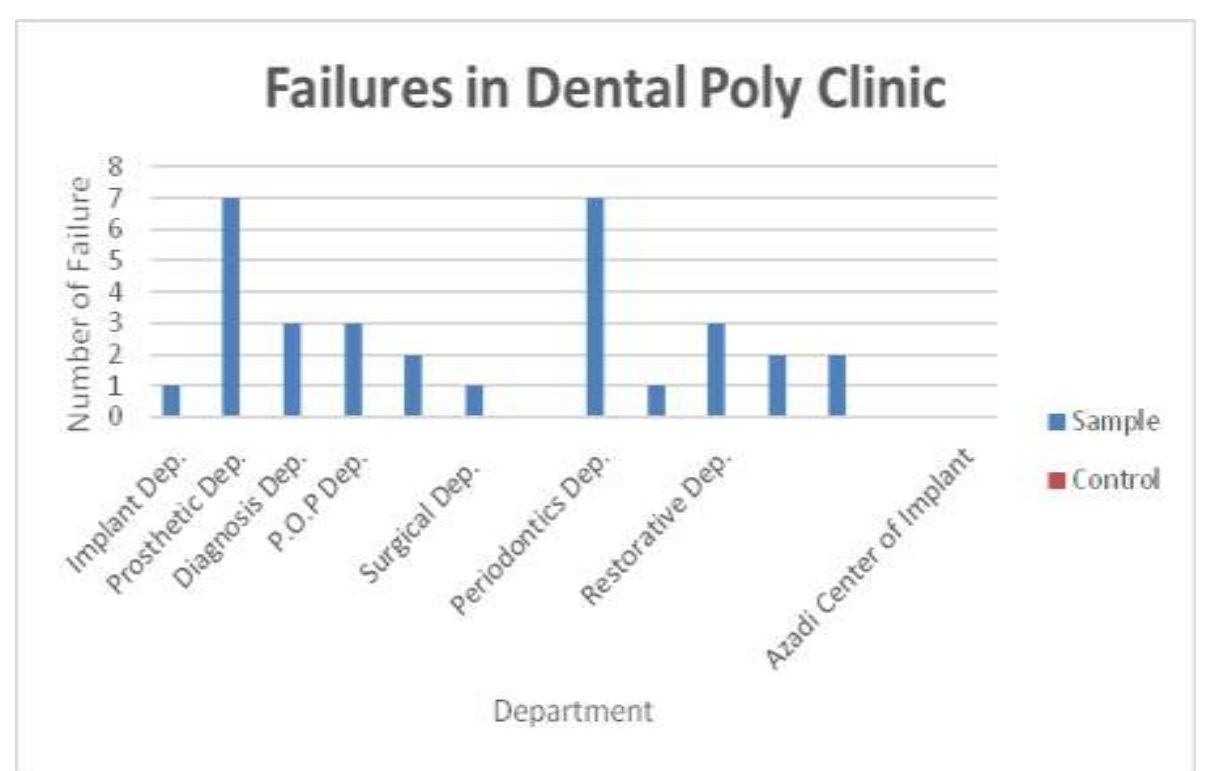

Figure (12) Scores of dental unit Failures in different Department of Polyclinic

Table (4) Descriptive Statistics for the different failures of departments in dental polyclinic.

\begin{tabular}{|l|l|l|l|l|l|}
\hline & $\mathrm{N}$ & Mean & Std. Deviation & Minimum & Maximum \\
\hline Sample & 28 & 1.14 & 1.957 & 0 & 7 \\
\hline Groups & 28 & 0.50 & 0.509 & 0 & 1 \\
\hline
\end{tabular}

Mann-Whitney Test Test Statistics

\begin{tabular}{|l|c|}
\hline & Sample \\
\hline Mann-Whitney U & 21.000 \\
\hline Wilcoxon W & 126.000 \\
\hline Z & -4.024 \\
\hline Asymp. Sig. (2-tailed) & $\mathbf{0 . 0 0 0}$ \\
\hline Exact Sig. [2*(1-tailed Sig.)] & $0.000^{\mathrm{b}}$ \\
\hline a. Grouping Variable: Groups & \\
b. Not correct for ties & \\
\hline
\end{tabular}

Failure in Dental Chairs in College of Dentistry 
A statistical analysis was performed to find the differences of failure in different Departments of College of Dentistry in Duhok City and the control \& the results revealed highly significant differences and these are presented in table (5) \&figure (13).

Table (5) Scoring failure in different Departments of Dental College in Duhok City

\begin{tabular}{|c|c|c|}
\hline Department & sample & Control \\
\hline Operative Dep. & 1 & 0 \\
\hline Prosthetic Dep. & 1 & 0 \\
\hline Surgical Dep. & 2 & 0 \\
\hline Periodontics Dep. & 1 & 0 \\
\cline { 2 - 3 } & 1 & 0 \\
\hline P.O.P Dep. & 1 & 0 \\
\hline X/Ray Dep. & 6 & 0 \\
\hline
\end{tabular}

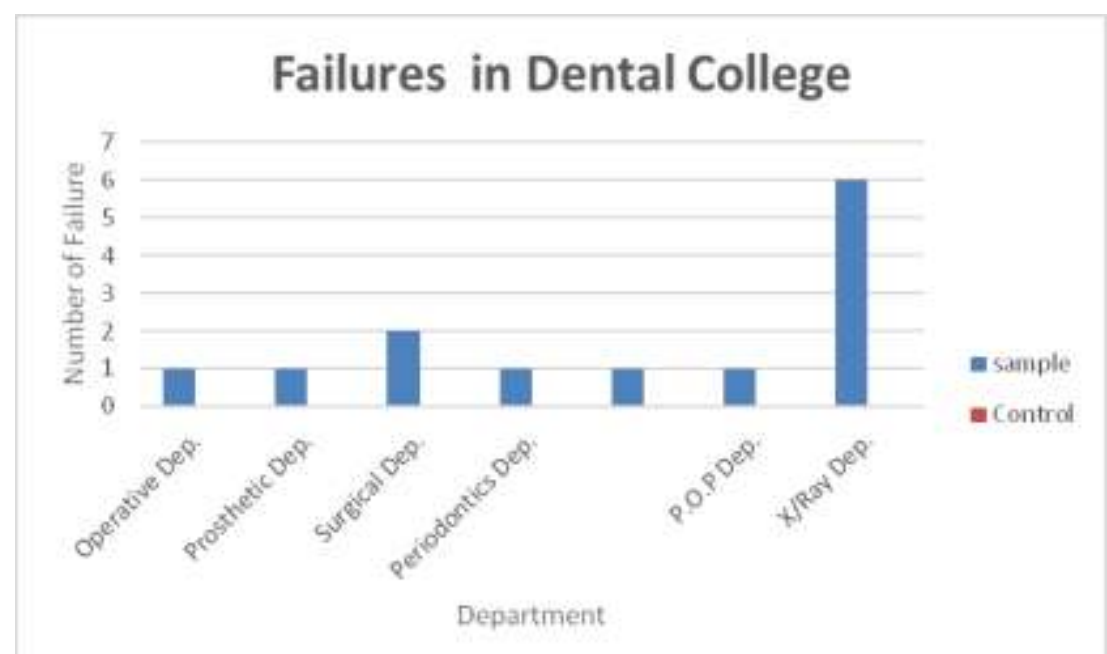

Figure (13) Scores of dental unit Failures in different Department of College of Dentistry

\begin{tabular}{l} 
Table (6) Descriptive Statistics for the different failures of departments \\
in dental College. \\
\hline
\end{tabular}

Mann-Whitney Test
\begin{tabular}{|l|l|}
\hline \multicolumn{1}{|c|}{ Test Statistics $^{\mathrm{a}}$} \\
\hline \multicolumn{1}{|c|}{${ }^{|c|}$ Sample } \\
\hline Mann-Whitney U & 0.000 \\
\hline Wilcoxon W & 28.000 \\
\hline Z & -3.430 \\
\hline Asymp. Sig. (2-tailed) & $\mathbf{0 . 0 0 1}$ \\
\hline Exact Sig. [2*(1-tailed Sig.)] & $0.001^{\mathrm{b}}$ \\
\hline a. Grouping Variable: Group \\
\hline b. Not corrected for ties. \\
\hline
\end{tabular}

There are a high significantly differences between control and sample groups in the number of failures in dental college $\backslash$ Duhok city.

\section{Discussion}

The distribution of dental unit in Duhok city (table 1\&figure 1) revealed that the percentage of these dental chairs according to their origin are different $45 \%$ from USA, 37\% from Italy 9\% from China, $7 \%$ Germany $\& 2 \%$ from Japan. This differences were due to that the import of these dental units came to the city in different times intervals \& and according to the progression \& expansions that happened, in addition to that due to the demand to the dental care increased. In the college of dentistry, University of Duhok, the origin of the dental units were from USA, this is due to that the clinical departments in the college started 3 years ago and the 
dental units came to the college in 2 successive periods, therefore the import was from one company (Aedic; USA). A statistical analysis was performed to find the differences of failure in different Departments of Dental Polyclinic according to the scoring mentioned previously. The results revealed highly significant differences and this could be due to frequent use of that instrument in that particular department in addition to that the performance of the instruments in regard to its manufactural origin.

A statistical analysis was performed to find the differences of failure in different Departments of College of Dentistry in Duhok City and the control \& the results revealed highly significant differences and this is could be to that the dental chair in the X-RAY department in the College of Dentistry was already old and transferred from the Health directorate of Duhok to the College and it was of different type (not from Aedic Company).

It was found from the results of failures, the failures in the dental chairs used in the polyclinic was higher In scoring than that of College of Dentistry this could be explained by the fact that the dental chair in the college were from aedic company and under warranty for two years while dental chairs in the polyclinic were from different companies without any contract of warranty.

\section{References}

[1]. Pickard, HM. Conservative dentistry in the past century. Br Dent J 1980; 149: 5-8. | Article | PubMed | ISI | ChemPort |

[2]. Gelbier S. Frederick Breese and London's first school dental clinic; Br Dent J 1981; 151: 309-311. | Article | PubMed | ISI | ChemPort |

[3]. McGehee, WHO, True, HA, Inskipp, EF. A textbook of operative dentistry, New York: McGraw-Hill Book Co Inc, 4th edition, 1956.

[4]. Allen, WH. The preservation of exposed dental pulps. Dent Cosmos 1866; 7: 423.

[5]. Atkinson, WH. The preservation of exposed dental pulps. Dent Cosmos 1866; 7: 425.

[6]. Hunter, FA. Saving pulps: a queer process. Dent Items Interest 1883; 5: 532.

[7]. Foote, GF. The preservation of opened dental pulps. Dent Cosmos 1866; 7: 428.

[8]. Tomes, C. A case of a widely exposed pulp. Br J Dent Sc 1896; 39: 577

[9]. Berman, D S. Pulp amputation and healing. J Dent Child 1958; 25: 84-104.

[10]. Teuscher, G, Zander, H. Preliminary report on pulpotomy. Northwestern University Dent Bull 1938; 39: 4.

[11]. Hunter, C. Mechanical Dentistry. London: Crosby, Lockwood and Co, 1906.

[12]. Hoffmann-Axthelm, W. History of Dentistry. Chicago: Quintessence Publishing Co Inc, 1981, p. 266 